\title{
İdrar Yolu Enfeksiyonu Tanılı Çocuklarda Ultrasonografi, Teknesyum-99m Dimerkaptosüksinik Asit Sintigrafisi ve Voiding Sistoüretrografi Bulgularının Uyumu
}

\author{
Compliance of Ultrasonography, Technetium-99m
}

Dimercaptosuccinic Acid Scintigraphy and Voiding

Cystourethrography Findings in Children With Urinary Tract Infection

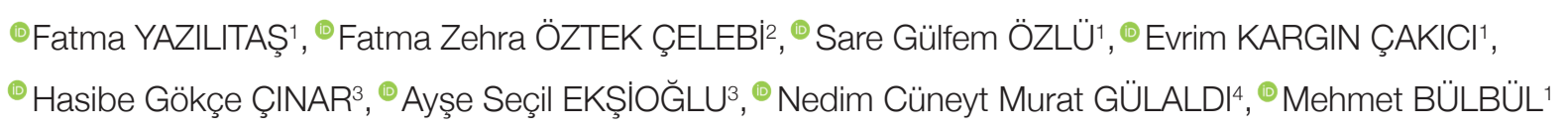

${ }^{1}$ S.B.Ü. Dr. Sami Ulus Kadın Doğum, Çocuk Sağığı ve Hastalıkları SUAM, Çocuk Nefroloji Kliniği, Ankara,Türkiye

2 S.B.Ü. Dr. Sami Ulus Kadın Doğum, Çocuk Sağlığı ve Hastalıkları SUAM, Pediatri Kliniği, Ankara,Türkiye

${ }^{3}$ S.B.Ü. Dr. Sami Ulus Kadın Doğum, Çocuk Sağlığı ve Hastalıkları SUAM, Radyoloji Kliniği, Ankara,Türkiye, Türkiye

${ }^{4}$ S.B.Ü. Dr. Sami Ulus Kadın Doğum, Çocuk Sağlığı ve Hastalıkları SUAM, Nükleer Tıp Bölümü, Ankara, Türkiye

\section{Öz}

Amaç: Bu çalışmanın amacı idrar yolu enfeksiyonu öyküsü olan çocuklarda ultrasonografi, teknesyum-99m dimerkaptosüksinik asit sintigrafisi ve voiding sistoüretrografi ile saptanan bulguların karşısaştıılması ve ayrıca önemli vezikoüreteral reflü ve renal hasar tespitini arttırırken invaziv testleri en aza indirmektir.

Gereç ve Yöntemler: Hastanemizde bir ylllik süre içinde ultrasonografi, teknesyum-99m dimerkaptosüksinik asit sintigrafi ve voiding sistoüretrografi uygulanan idrar yolu enfeksiyonu tanilı çocuk hastaların tıbbi kayıtları retrospektif olarak incelendi.

Bulgular: Toplam 99 (\%40.9) erkek (ortalama yaşı $1.7 \pm 3.1$ yll) ve 143 (\%59.1) kız (yaş ortalaması $5.3 \pm 3.9$ yll) hasta çalışmaya alındı. Ultrasonografinin 196 (\%81.0) hastada anormal olduğu saptandı. Vezikoüreteral reflü 102 (\%42.1) hastada gözlendi. Vezikoüreteral reflü evresi 4-5 olan hastaların \%65.7'sinde teknesyum-99m dimerkaptosüksinik asit sintigrafisinde renal parankimal skar saptandı.

Sonuç: İdrar yolu enfeksiyonu ilişkili vezikoüreteral reflü saptanması için tarama yöntemi olan ultrasonografi vezikoüreteral reflüyü tamamen öngörememektedir. Teknesyum-99m dimerkaptosüksinik asit sintigrafisi ultrasonografiye göre daha güvenilir bir inceleme olsa da vezikoüreteral reflü saptanması için günümüzde voiding sistoüretrografi en güvenilir yöntemdir.

Anahtar Sözcükler: Çocuk, Ultrasonografi, İrar Yolu Enfeksiyonu, Vezikoüreteral reflü, Voiding sistoüretrografi

\begin{abstract}
Objective: The aim of this study was to compare the findings of ultrasonography, technetium-99m dimercaptosuccinic acid scintigraphy and voiding cystourethrography in children with a history of urinary tract infection, and also to increase the detection of significant vesicoureteral reflux and renal damage, while minimizing invasive tests.

Material and Methods: The medical records of pediatric patients with urinary tract infection who underwent ultrasonography, technetium-99m dimercaptosuccinic acid scintigraphy and voiding cystourethrography within one year in our hospital were evaluated retrospectively.

Results: A total of 99 (40.9\%) boys (mean age $1.7 \pm 3.1$ years) and $143(59.1 \%)$ girls (mean age $5.3 \pm 3.9$ years) were included in the study. Ultrasonography was found to be abnormal in $196(81.0 \%)$ patients. Vesicoureteral reflux was observed in 102 (42.1\%) patients. Renal parenchymal scar was detected on technetium-99m dimercaptosuccinic acid scintigraphy scans in $65.7 \%$ of patients with vesicoureteral reflux stages 4 and 5 .

Conclusion: Ultrasonography, which is a screening method for the detection of vesicoureteral reflux related to urinary tract infection, cannot completely predict vesicoureteral reflux. While technetium-99m dimercaptosuccinic acid scintigraphy is more reliable than ultrasonography, voiding cystourethrography is currently the most reliable method for detection of vesicoureteral reflux.
\end{abstract}

Key Words: Children, Ultrasonography, Urinary Tract Infection, Vesicoureteral reflux, Voiding cystourethrography

Yazışma Adresi / Correspondence Address:

Fatma YAZILITAS

S.B.Ü Dr. Sami Ulus Kadın Doğum, Çocuk Sağı̆̆ı ve Hastalıkları SUAM,

Çocuk Nefroloji Kliniği, Ankara, Türkiye

E-posta:fmeryemesra@yahoo.com
Geliş tarihi / Received : 11.10 .2019 Kabul tarihi / Accepted : 09.04.2019 Elektronik yayın tarihi : :25.07.2019 Online published

DOI: 10.12956/tchd.512969 


\section{GiRiş}

Çocukluk çağında ultrasonografi (US), invaziv olmayan bir tetkik olarak üriner sistemin hem konjenital hem de edinilmiş hastalıklarının tanısında ve takibinde görüntüleme için en iyi başlangıç tanısal yöntemdir (1). İdrar yolu enfeksiyonu öyküsü olan çocuklarda erken dönemde uygulanması önerilmektedir (2).

Voiding sistoüretrografi (VCUG), hem vezikoüreteral reflü tanısı hem de mesane ve üretranın anatomik yapısının değerlendirilmesi için en iyi görüntüleme yöntemi olmakla birlikte invaziv bir işlemdir. VCUG endikasyonları arasında idrar yolu enfeksiyonu, antenatal veya postnatal olarak tanısı konmuş hidronefroz, duplikasyon, nörojen mesane ve şüpheli posterior üretral valv değerlendirilmesi yer alır $(1,2)$.

Teknesyum-99m dimerkaptosüksinik asit (DMSA) sintigrafisi, kısa ömürlü radyoizotop ile renal korteksin görüntülenmesi için uygun bir yöntemdir. DMSA sintigrafisi akut-kronik piyelonefrit veya böbrek parankim anormalliklerine bağlı parankimal hasarın varlığını kanıtlamak, kortikal skar, rölatif böbrek büyüklüğü böbrek enfarktları ve konjenital böbrek anomalileri (çift toplayıcı sistem, at nalı böbrek, multikistik displastik böbrek ve ektopik böbrek) ile ilgili bilgi elde etmek için tercih edilen görüntüleme yöntemidir $(3,4)$.

Bu çalışmada idrar yolu enfeksiyonu geçiren çocuklarda vezikoüreteral reflü ve renal hasar bulgularının birbirleri ile uyumunu değerlendirmek amacı ile US, VCUG ve DMSA ile saptanan görüntüleme bulgularının karşılaştırıması amaçlandı.

\section{GEREÇ ve YÖNTEMLER}

Çocuk Nefrolojisi Kliniğinde idrar yolu enfeksiyonu tanısı ile izlenen, bir yıllık sürede US, DMSA ve VCUG görüntülemeleri uygulanan ve yaşları 0-17 yaş arasında değişen çocuk hastalar geriye dönük olarak değerlendirildi. Bu çalışmaya idrar yolu enfeksiyonu (üst ve alt üriner sistem IYE, tekrarlayan IYE, komplike IYE veya komplike olmayan ateşli iYE) tanısı ile izlenen tüm hastalar dahil edildi. Her üç tetkiki yapılmamış olanlar, asemptomatik bakteriürisi bulunanlar ve uygun idrar örneği alınmayan çocuklar çalışma dışı bırakıldı. Yaş, cinsiyet, ateş, üreyen mikroorganizma gibi klinik ve laboratuvar verileri, US, DMSA ve VCUG görüntüleme sonuçları hasta dosyalarından kaydedildi.

Yenidoğanlarda ve bebeklerde genital temizlik sonrasında sonda uygulanması ile alınan idrar örnekleri, idrar kontrolü olan çocuklarda ise orta akım idrar yöntemi ile alınan idrar örnekleri kaydedildi. İdrar yolu enfeksiyonu (IYE) ateş $\left(38^{\circ} \mathrm{C}\right.$ ve/veya daha yüksek) veya tipik semptomların varlığı ve eş zamanlı temiz orta akım veya sonda ile alınan idrar numunesinde en az 100.000 koloni birim (CFU)/ml'den oluşan tek bir tür patojen mikroorganizmanın üremesi ile birlikte piyüri ( $>5$ beyaz kan hücre/bir büyütme alanı) ve/veya idrarda değişiklik (lökosit esteraz, nitrit pozitifliği) olarak tanımlandı (5). Tekrarlayan IYE aşağıdakilerden herhangi birinin varlığı olarak tanımlandı: (a) iki veya daha fazla akut piyelonefrit/üst üriner sistem enfeksiyonu varlığı; (b) bir akut piyelonefrit/üst üriner sistem enfeksiyonu ve iki veya daha fazla sistit/alt üriner sistem enfeksiyonu varlığı; (c) üç veya daha fazla sistit/alt üriner sistem enfeksiyonu varlığı (5).

Hastalara çocuklarda deneyimli radyologlar tarafından yapılan üriner sistem US sonuçları kaydedildi. Hidronefroz $(\mathrm{HN})$, renal pelvikalisiyel sistemin dilatasyonu olarak tanımlandı. Hidronefroz, böbrek pelvis ön-arka çap ölçülerek uygun sınıflama kriterleri kullanılarak derecelendirildi (6). IYE tedavisinden en erken 4 hafta sonra çekilen ve pediatrik radyolog tarafından mesane ve üretra anatomisinin değerlendirildiği VCUG raporları kaydedildi. VUR evrelemesi uluslararası vezikoüreteral reflü çalışma komitesi önerilerine göre yapıldı (7). Her iki üretere reflü tespit edildiğinde en yüksek evre kaydedildi.

Aktif idrar yolu enfeksiyonundan en az 120 gün sonra uygulanan DMSA sintigrafi bulguları kaydedildi. Diferansiyel renal fonksiyon normal aralıkta ve radyoizotop alımı skar kanıtı olmadan homojen ise, kortikal hipoaktivite yoksa DMSA normal olarak kabul edildi. Dış kontürlerde belirgin lokalize deformite olması ve volüm kaybı, kortekste hacim azalması skar olarak kabul edildi (8). Mesane duvarında kalınlaşma, trabekülasyon, divertikül, ve nörojen mesane bulguları mesane bozukluğu olarak değerlendirildi.

\section{İstatistiksel Değerlendirme}

İstatistiksel değerlendirme SPSS 17 (SPSS Inc. Chicago, IL, ABD) paket programı kullanılarak yapıldı. Verilerin normal dağılımı Kolmogorov-Smirnov testi ile kontrol edildi. Verilerin tanımlayıcı özellikleri (ortalama, ortanca, sayı ve yüzde) bulundu. İki grup karşılaştırılırken normal dağılan sayısal değişkenlerde student t test, normal dağılmayan sayısal değişkenlerde Mann-Whitney $U$ test kullanıldı. VUR için risk faktörü araştırılırken önce tek değişkenli logistik regresyon yapıldı. Daha sonra tek değişkenli sonuçlarda $p<0.25$ çıkan değişkenler ile çoklu regresyon yapıldı ve risk faktörü belirlenmeye çalışıldı. Eğer $p<0.05$ ise istatistiksel olarak anlamlı kabul edildi.

\section{BULGULAR}

Yaşları 0-17 yaş arasında olan ve US, DMSA ve VCUG görüntüleme yöntemleri uygulanan 99'u (\%40.9) erkek, 143'ü (\%59.1) kız toplam 242 hasta çalışmaya dahil edildi. Yaş ortalaması $4.3 \pm 4.4$ (ortanca 3 yıl)'dı. Erkeklerin ortalama yaşı $1.7 \pm 3.1 \mathrm{yıl}(0-15 \mathrm{yll})$, kızların yaş ortalaması $5.3 \pm 3.9 \mathrm{yll}(0-17$ yıl) olup kızların yaşları istatistiksel olarak anlamlı şekilde daha büyük bulundu ( $p<0.001$ ) (Tablo I). Hastaların demografik ve klinik verileri Tablo 1'de verildi.

Hastaların 196'sında (\%81.0) anormal renal US bulguları saptandı. Renal US'de anormal bulgular hastaların 56'sında 
Tablo I: Hastaların cinsiyete göre demografik ve klinik değerlendirmeleri.

\begin{tabular}{|c|c|c|c|c|}
\hline & $\begin{array}{c}\text { Total } \\
\text { Sayı (yüzde) }\end{array}$ & $\begin{array}{c}\text { Erkek } \\
\text { Sayı (yüzde) }\end{array}$ & $\begin{array}{c}\text { Kız } \\
\text { Sayı (yüzde) }\end{array}$ & p \\
\hline $\begin{array}{l}\text { Yaş } \\
0-1 \text { yaş } \\
1 \text { yaş ve üzeri }\end{array}$ & $\begin{array}{c}69(28.5) \\
173(71.5)\end{array}$ & $\begin{array}{l}51(73.9) \\
48(27.7)\end{array}$ & $\begin{array}{r}18(26.1) \\
125(72.3)\end{array}$ & $\begin{array}{l}<0.001 \\
<0.001\end{array}$ \\
\hline $\begin{array}{l}\text { Tekrarlayan iYE öyküsü } \\
\text { Yüksek ateş ile birlikte IYE öyküsü } \\
\text { Yüksek CRP ile birlikte IYE öyküsü }\end{array}$ & $\begin{array}{l}197(81.4) \\
148(63.2) \\
100(51.5)\end{array}$ & $\begin{array}{l}73(73.7) \\
54(54.5) \\
34(40.5)\end{array}$ & $\begin{array}{r}124(86.7) \\
94(69.6) \\
66(60.0)\end{array}$ & $\begin{array}{l}0.012 \\
0.018 \\
0.007\end{array}$ \\
\hline $\begin{array}{l}\text { İdrar Kültüründe Üreyen Mikroorgan } \\
\text { E. Coli } \\
\text { Diğer }\end{array}$ & $\begin{array}{r}167(69.0) \\
75(31.0)\end{array}$ & $\begin{array}{l}48(48.5) \\
51(51.5)\end{array}$ & $\begin{array}{r}119(83.2) \\
24(16.8)\end{array}$ & $\begin{array}{l}<0.001 \\
<0.001\end{array}$ \\
\hline $\begin{array}{l}\text { VUR } \\
\text { Evre } 1-2-3 \\
\text { Evre } 4-5\end{array}$ & $\begin{array}{l}67(65.7) \\
35(34.3)\end{array}$ & $\begin{array}{l}24(63.2) \\
14(36.8)\end{array}$ & $\begin{array}{l}43(67.2) \\
21(32.8)\end{array}$ & $\begin{array}{l}0.291 \\
0.705\end{array}$ \\
\hline Anormal US bulgusu & $196(81.0)$ & 85 (85.9) & $111(77.6)$ & 0.108 \\
\hline Renal Parankimal Skar & 109 (45.2) & $34(34.7)$ & $75(52.4)$ & 0.007 \\
\hline
\end{tabular}

iYE: Idrar yolu enfeksiyonu, E.coli: Escherichia coli, CRP: C reaktif protein, US: Ultrasonografi, VUR: Vezikoüreteral reflü.

Tablo II: Hastaların demografik ve klinik özelliklerine göre DMSA sintigrafisi bulguları.

\begin{tabular}{|c|c|c|c|}
\hline & \multicolumn{2}{|c|}{$\begin{array}{l}\text { DMSA Sintigrafisinde } \\
\text { Renal Parankimal Skar }\end{array}$} & \multirow[t]{2}{*}{$\mathbf{p}$} \\
\hline & Yok; n (\%) & Var; n (\%) & \\
\hline $\begin{array}{l}\text { Yaş } \\
0-1 \text { yaş } \\
1 \text { yaş ve üzeri }\end{array}$ & $\begin{array}{l}55(79.7) \\
77(44.8)\end{array}$ & $\begin{array}{l}14(20.3) \\
95(55.2)\end{array}$ & $<0.001$ \\
\hline Yüksek ateş ile birlikte iYE öyküsü & $75(59.5)$ & $72(67.3)$ & 0.221 \\
\hline Yüksek CRP ile birlikte IYE öyküsü & $43(41.0)$ & $57(64.8)$ & 0.001 \\
\hline Hidronefroz varlığı & $102(77.9)$ & $58(54.2)$ & $<0.001$ \\
\hline VUR varlığı & 36 (27.3) & 66 (60.6) & $<0.001$ \\
\hline
\end{tabular}

iYE: Idrar yolu enfeksiyonu, E.coli: Escherichia coli, CRP: C reaktif protein, VUR: Vezikoüreteral reflü, DMSA: Teknesyum-99m dimerkaptosüksinik asit sintigrafisi.

(\%23.1) sağ böbrekte, 74'ünde (\%30.6) sol böbrekte ve 66 'sında (\%27.3) her iki böbrekte gözlendi. Anormal US bulgusu olanların 85'inde (\%43.4) VUR tespit edildi ( $p=0.428)$. Normal US bulgularına sahip olan hastaların VCUG ile 17'sinde (\%36.9) VUR, üçünde (\%6.5) mesane bozukluğu ve ikisinde (\%4.3) posterior üretral valv (PUV) saptandı. US bulguları normal olan 29 (\%63.0) hastada ise DMSA sintigrafisinde renal parankimal skar gözlendi. DMSA sintigrafisinde renal parankimal skar 109 (\%45.0) hastada saptandı ve renal parankimal skar, kızlarda istatistiksel anlamlı olarak daha yüksek sıklıkta gözlendi $(p<0.001)$ (Tablo II). DMSA sintigrafisiyle hastaların 35'nde (\%14.5) sağ böbrekte, 40'nda (\%11.6) sol böbrekte ve 25'inde (\%10.3) her iki böbrekte renal parankimal skar saptandı. DMSA sintigrafisi bulguları Tablo Il'de verildi.

DMSA sintigrafisinde renal parankimal skar saptanan hastaların VCUG ile görüntülenmesi sonucunda beșinde (\%4.6) mesane bozukluğu, beşinde (\%4.6) PUV ve 66'sında (\%60.6) VUR tespit edildi. VUR evresi 1-2-3 olan hastaların \%64.2'sinde, VUR evresi 4 ve 5 olan hastaların \%65.7'sinde DMSA sintigrafisi ile renal parankimal skar tespit edildi. DMSA ile skar saptanan ancak VCUG ile VUR gözlenmeyen 41 hasta (\%37.6) vardı. VUR gözlenmeyen bu hastaların 27'sinde (\%65.8) ateşle birlikte IYE geçirme öyküsü, 21'inde (\%51.2) IYY sırasında yüksek CRP ve 35 'inde (\%85.4) tekrarlayan IYE öyküsü vardı.

Hem DMSA sintigrafisinde renal parankimal skar hem de VCUG ile VUR saptanması erkeklere göre kızlarda daha fazla gözlendi (Şekil 1).

Idrar yolu enfeksiyonu olan çocuklarda VCUG ile 102 (\%42.1) VUR, dokuz (\%3.7) mesane anomalisi, dokuz (\%3.7) PUV ve bir (\%0.4) vesikovajinal fistül tespit edildi. Hastaların 18'nde (\%7.4) sağ böbreğe VUR, 28'nde (\%11.6) sol böbreğe VUR ve 56'sında (\%23.1) her iki böbreğe VUR olduğu gözlendi. VUR'u olan hastaların klinik bulguları ile DMSA sintigrafisi bulguları karşılaştıııldı̆ında renal parankimal skar varlığı $(p<0.001)$, tekrarlayan IYE öyküsü ( $p=0.007)$, ve IYE sırasında yüksek ateş varlığı $(p=0.021)$ arasında istatistiksel olarak anlamlı ilişki saptandl. 
Tablo III: İdrar yolu enfeksiyonu olan çocuklarda DMSA sintigrafisi ve US ile vezikoüreteral reflü (VUR) arasındaki ilişki.

\begin{tabular}{|c|c|c|c|c|c|c|c|c|c|c|c|c|}
\hline \multirow{2}{*}{ VUR } & \multicolumn{2}{|c|}{ US } & \multirow[b]{2}{*}{$\mathbf{p}$} & \multicolumn{2}{|c|}{ DMSA } & \multirow[b]{2}{*}{$\mathbf{p}$} & \multicolumn{2}{|c|}{ DMSA ve USa } & \multirow[b]{2}{*}{ p } & \multicolumn{2}{|c|}{ DMSA veya US b } & \multirow[b]{2}{*}{$\mathbf{p}$} \\
\hline & Anormal & Normal & & Anormal & Normal & & Anormal & Normal & & Anormal & Normal & \\
\hline Yok & 111 & 29 & \multirow{6}{*}{0.336} & 43 & 96 & \multirow{6}{*}{$<0.001$} & 26 & 114 & \multirow{6}{*}{$<0.001$} & 128 & 12 & \multirow{6}{*}{0.650} \\
\hline Evre 1 & 5 & 0 & & 3 & 2 & & 3 & 2 & & 5 & 0 & \\
\hline Evre 2 & 17 & 6 & & 12 & 11 & & 9 & 14 & & 20 & 3 & \\
\hline Evre 3 & 31 & 8 & & 28 & 11 & & 22 & 17 & & 37 & 2 & \\
\hline Evre 4 & 19 & 3 & & 15 & 7 & & 13 & 9 & & 21 & 1 & \\
\hline Evre 5 & 13 & 0 & & 8 & 5 & & 8 & 5 & & 13 & 0 & \\
\hline Total & 196 & 46 & & 109 & 132 & & 81 & 161 & & 224 & 18 & \\
\hline
\end{tabular}

VUR: Vezikoüreteral reflü, US: Ultrasonografi, DMSA: Teknesyum-99m dimerkaptosüksinik asit sintigrafisi,

DMSA ve USa: Hem Teknesyum-99m dimerkaptosüksinik asit sintigrafisinde hem de ultrasonografide anormal bulgusu olan hastalar

DMSA veya US ${ }^{b}$ : Teknesyum-99m dimerkaptosüksinik asit sintigrafisinde ya da ultrasonografide anormal bulgusu olan hastalar

İdrar yolu enfeksiyonu geçiren hastaların US, DMSA sintigrafisi ve VUR bulguları tablo III'de özetlendi.

Çok değişkenli lojistik regresyon analizinde VUR için bağımsız risk faktörleri incelendi. VUR riskini DMSA'da renal parankimal skar varlığıııı 3.6 kat (\%95Cl: 2.0-6.6) artırdığı, tekrarlayan idrar yolu enfeksiyonunun 2.5 kat (\%95Cl: 1.1-5.6) arttırdığı ve idrar yolu enfeksiyonu sırasında yüksek ateş varlığının ise 2.0 kat (\%95Cl: 1.1-3.7) kat artırdığı saptandı.

\section{TARTIŞMA}

Bu çalışmada IYE geçiren çocuklarda VCUG ile \%42.1 sıklıkta VUR tespit edildi. Bulgularımız IYE geçiren çocuklarda literatürde \%25-40 olarak bildirilen VUR sıklığı ile uyumluydu $(9,10)$. Bu çalışmada kızların sayısı erkeklere göre daha fazlaydı. Bu bulgu, tekrarlayan IYE'nin kızlarda daha sık görülmesi ile ilişkili olabilir. Çalışmamı sonucunda, tekrarlayan IYE öyküsü olanlarda, IYE sırasında yüksek ateş saptananlarda ve DMSA sintigrafisinde renal parankimal skar hasarı gözlenen hastalarda ileri evre VUR sıklığının istatistiksel anlamlı olarak daha fazla olduğu gösterilmiştir. Bu nedenle tekrarlayan IYE öyküsü, IYE sırasında yüksek ateş ve DMSA sintigrafisinde renal parankimal skar hasarı olan hastalarda VCUG uygulamasının gerekli olduğunu düşünmekteyiz. Çalışmamızın bulguları, literatür ile de uyumlu olacak şekilde IYE ilişkili VUR tanısında US'nin, risk altındaki hastaların belirlenmesinde tek başına yetersiz kalabileceğini göstermektedir $(11,12)$. Ultrasonografi, minimal rahatsızlık hissi dışında uygulanması kolay ve riski olmayan non-invaziv bir tetkiktir. Ateșli IYE tanısı sırasında ve sonrasında ilk görüntüleme çalışması amacıyla tarama yöntemi olarak yapilacak görüntüleme yöntemidir $(1,2,13)$. US, American Academy of Pediatrics (AAP) tarafindan IYE geçirenlerde VUR'un varlı̆ı̆ını tahmin etmekte tarama yöntemi olarak önerilmektedir (14). US bulgularının normal olması VUR olasılı̆ını ekarte ettirmez dolayısı ile özellikle de atipik klinik seyirli IYE olgularında ve renal skar mevcut ise VCUG uygulanması daha doğru bir yaklaşım olarak düşünülmektedir (14-16). Bununla birlikte IYE sonrası VUR açısından çocukların değerlendirilmesi için VCUG'un zamanlaması ve endikasyonu konusunda fikir birliği yoktur. Çalışmamızda US normal olan hastaların \%36.9'unda VUR, \%6.5'inde mesane bozukluğu, \%4.3'ünde PUV gözlendi. AAP ve National Institude for Health and Clinical Excellence (NICE) kllavuzlarına göre US normal olduğunda VCUG endikasyonu bulunmamaktadır $(14,17)$. Bulgularımı; NICE ve AAP kilavuzlarına göre görüntüleme yapıldığında VCUG ile saptadığımız \%7.4 sıklığındaki patolojinin atlanabilecek olduğunu göstermiştir. VUR için risk altında olan hastaların bir kısmını tespit etmede tek başına US'un yetersiz olacağının saptanması NICE ve AAP klavuzları için en fazla eleştiri nedeni olmuştur (18-20).

Çalışmamızda DMSA sintigrafisinde renal parankimal skar saptanan hastaların \%39.4'ünde VUR tespit edilmedi. VUR yokluğunda renal skar saptanması, prenatal dönemde mevcut bir VUR'un sonucu, hidronefrozun immatür böbreklerde yüksek mesane basıncının olușturduğu hasara bağı küçük displazik böbrek gelişimine neden olması ile veya mevcut VUR'un kendiliğinden rezolüsyonu ile açıklanabilir (21). Çocukluk çağı IYE sonrası renal skarlaşma hem VUR varlı̆ı̆ıda hem de yokluğunda ortaya çıkabilir $(22,23)$. Ateșli ve tekrarlayan IYE geçiren hastalarda renal parankimal skar sıklı̆ı̆ın ateşli olmayan IYE geçirenlere göre daha yüksek olduğu bilinmektedir. IYE sırasında renal parankim inflamasyonun eșlik etmesi VUR olmadan renal parankimal skar bulunması için bir açıklama olabilir. Bu sonuçlar renal parankimal skar oluşumunda renal parankimal enfeksiyon varlı̆ıının önemini gösterebilir. Preda ve arkadașları, IYE geçiren bebeklerde ileri evre VUR olanların \%96'sında anormal DMSA sintigrafisi saptamıș ve normal bir DMSA sintigrafisinin VCUG'u gereksiz hale getirdiğini belirtmiştir (24). Fouzas ve ark.(25) ise, DMSA sintigrafi ve ultrasonografi bulguları normal olan 296 çocuğun 12'sinde VUR saptamıştır. Tekgül ve ark. (26) IYE sonrası DMSA sintigrafisi normal olan olgularda VCUG uygulanmadığı takdirde \%5-27 sıklıkta VUR tanısının atlanabileceğini bildirmişlerdir. DMSA sintigrafisinde renal parankimal skar saptanmadığı durumlarda VCUG çekilmesi radyasyon maruziyeti ve düşük evre VUR saptanmasının klinik 


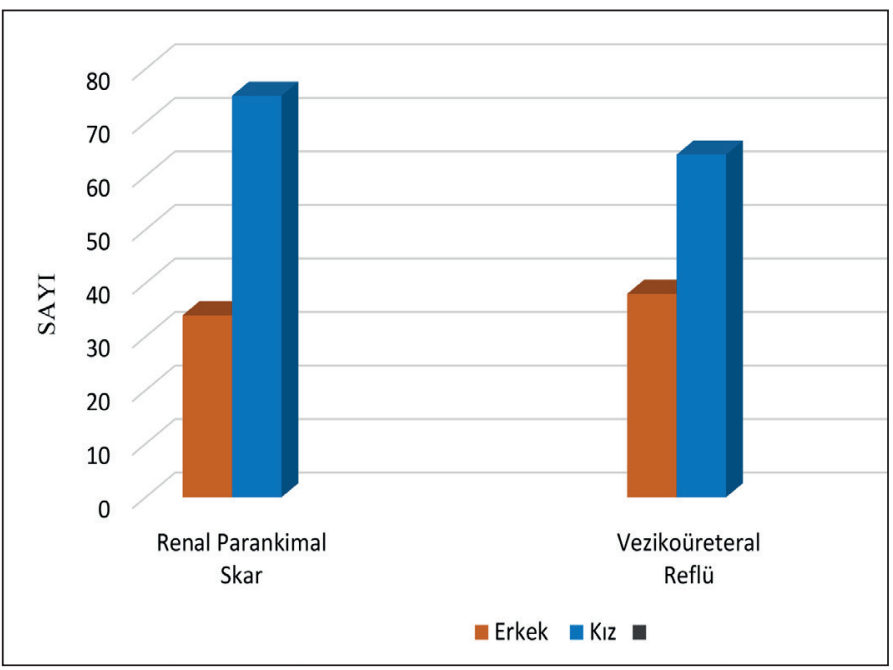

Önemi az olduğundan günümüzde çoğu yazar tarafindan önerilmemektedir. Kronik böbrek hastalı̆ına ilerleme riski yüksek olanların belirlenmesi amaç olarak önerilmektedir. DMSA sintigrafisinde skar saptanmamasına rağmen VUR mevcut olabileceği bilinmekle birlikte bu çalışma sonucunda DMSA sintigrafisinde renal parankimi normal olan hastalarda VCUG çekilmesi açısından yorum yapmak zordur. Shaikh ve ark.(27) normal bir DMSA sintigrafisi olan bir çocukta yüksek dereceli VUR olasılığının <\% 1 olmasına rağmen, DMSA'nın yüksek dereceli VUR için bir tarama testi olarak kullanılmasının sorgulanması gerektiğini bildirmiştir.

Pecile ve ark.(28) renal skar olasılı̆ının yaș ile korele olarak yüksek olduğunu bildirmiştir. Bizim çalışmamızda da DMSA sintigrafisinde renal parankimal skar varlığının, yaş arttıkça istatistiksel olarak anlamlı şekilde artığı gözlenmiştir $(p<0.001)$. Bu sonuç yaş arttıkça hastalarımızda tekrarlayan IYE sıkığının artmasına bağı olabilir.

Çalışmamızın en önemli kısıtlayıcı faktörleri retrospektifbir çalışma olmasından kaynaklanmaktadır. Bu nedenle hem radyolojik değerlendirmeler hem de DMSA sintigrafisi merkezimizde uygulanmış olmasına rağmen değerlendirmeler aynı radyolog veya aynı nükleer tıp uzmanı tarafından çekilememiş̧ir. Bununla birlikte görüntülemeler retrospektif olarak alanında uzman iki radyolog ve nükleer tıp uzmanı tarafından tekrar gözden geçirilerek birlikte yorumlanmıştır. Ayrıca hasta sayımız kesin sonuçlara ulaşmak açısından yeterli değildir. Çallşma izlem süremizin bir yll gibi kısa bir süre olması da çalışmamız için diğer bir kısıtlayıcı faktördür. Diğer bir kısıtlama ise hastanemizin üçüncü basamak bir sağlik merkezi olmasına ve ülkemizin her yerinden hasta kabul edilmesine rağmen tek merkez sonuçları olması nedeniyle bulgularımı ülke genelini tam olarak yansıtmayabileceğidir.

\section{SONUÇLAR}

Çalışmamızda pediatrik hastalarda idrar yolu enfeksiyonu ilişkili vezikoüreteral reflü saptanmasında, US ve DMSA sintigrafisinin rutin kullanımının VCUG uygulama intiyacını ortadan kaldırmaya
Şekil 1: Cinsiyet ile renal parankimal skar ve vezikoüreteral reflü arasındaki ilişki.

yetmeyebileceği belirlenmiştir. Ultrasonografi ve DMSA sintigrafisi VUR'u tamamen öngörememektedir. VCUG, VUR saptanması için daha güvenilir bir yöntem olarak görünmektedir.

\section{Finansal Kaynak}

Bu çalışma sırasında, yapılan araştırma konusu ile ilgili doğrudan bağlantısı bulunan herhangi bir ilaç firmasından, tıbbi alet, gereç ve malzeme sağlayan ve/veya üreten bir firma veya herhangi bir ticari firmadan, çalışmanın değerlendirme sürecinde, çalışma ile ilgili verilecek kararı olumsuz etkileyebilecek maddi ve/veya manevi herhangi bir destek alınmamıştır.

\section{Çıkar Çatışması}

Bu çalışma ile ilgili olarak yazarların ve/veya aile bireylerinin çıkar çatışması potansiyeli olabilecek bilimsel ve tıbbi komite üyeliği veya üyeleri ile ilişkisi, danışmanlık, bilirkişilik, herhangi bir firmada çalıșma durumu, hissedarlık ve benzer durumları yoktur.

\section{KAYNAKLAR}

1. Riccabona M, Avni FE, Blickman JG, Dacher JN, Darge K, Lobo $\mathrm{ML}$, et al. Imaging recommendations in paediatric uroradiology: Minutes of the ESPR workgroup session on urinary tract infection, fetal hydronephrosis, urinary tract ultrasonography and voiding cystourethrography, Barcelona, Spain, June 2007. Pediatr Radiol 2008;38:138-45.

2. Stein R, Dogan HS, Hoebeke P, Kočvara R, Nijman RJ, Radmayr C, et al. European Association of Urology; European Society for Pediatric Urology. Urinary tract infections in children: EAU/ESPU guidelines. Eur Urol 2015;67:546-58.

3. Gordon I. Indications for 99m-technetium dimercaptosuccinic acid scan in children. J Urol 1987;137:464-7.

4. Rossleigh MA. Renal cortical scintigraphy and diuresis renography in infants and children. J Nucl Med 2001;42: 91-5.

5. National Collaborating Centre for Women's and Children's Health (UK). Urinary Tract Infection in Children: Diagnosis, Treatment and Long-term Management. London: RCOG Press; 2007 Aug. PMID: 21290637 
6. Nguyen HT, Benson CB, Bromley B, Campbell JB, Chow J, Coleman B, et al. Multidisciplinary consensus on the classification of prenatal and postnatal urinary tract dilation (UTD classification system). J Pediatr Urol 2014;10:982-98.

7. Fernbach SK, Feinstein KA, Schmidt MB. Pediatric voiding cystourethrography: a pictorial guide. Radiographics 2000;20:15568.

8. Piepsz A, Colarinha P, Gordon I, Hahn K, Olivier P, Roca I ,et al. Guidelines for 99mTc-DMSA scintigraphy in children. Eur J Nucl Med 2001;28:BP37-BP41.

9. Cleper R, Krause I, Eisenstein B, Davidovits M. Prevalence of vesicoureteral reflux in neonatal urinary tract infection. Clin Pediatr (Phila) 2004;43:619-25.

10. Ristola MT, Hurme T. NICE Guidelines Cannot Be Recommended for Imaging Studies in Children Younger Than 3 Years with Urinary Tract Infection. Eur J Pediatr Surg 2015;25:414-20.

11. Ristola MT, Löyttyniemi E, Hurme T. Factors Associated with Abnormal Imaging and Infection Recurrence after a First Febrile Urinary Tract Infection in Children. Eur J Pediatr Surg 2017;27:1429.

12. Kimata T, Kitao T, Yamanouchi S, Tsuji S, Kino M, Kaneko K. Voiding cystourethrography is mandatory in infants with febrile urinary tract infection. Tohoku J Exp Med 2013;231:251-5.

13. Practice parameter: The diagnosis, treatment, and evaluation of the initial urinary tract infection in febrile infants and young children. American Academy of Pediatrics. Committee on Quality Improvement. Subcommittee on Urinary Tract Infection. Pediatrics 1999;103:1052.

14. Subcommittee on Urinary Tract Infection, Steering Committee on Quality Improvement and Management, Roberts KB. Urinary tract infection: clinical practice guideline for the diagnosis and management of the initial UTI in febrile infants and children 2 to 24 months. Pediatrics 2011;128:595-610.

15. Jodal U, Lindberg U. Guidelines for management of children with urinary tract infection and vesico-ureteric reflux. Recommendations from a Swedish state-of-the-art conference. Swedish Medical Research Council. Acta Paediatr Suppl 1999;88:87-9. PMID: 10588276

16. Gordon I, Barkovics M, Pindoria S, Cole TJ, Woolf AS. Primary vesicoureteric reflux as a predictor of renal damage in children hospitalized with urinary tract infection: a systematic review and meta-analysis. J Am Soc Nephrol 2003;14:739-44.

17. National Collaborating Centre for Women's and Children's Health (UK). Urinary Tract Infection in Children: Diagnosis, Treatment and Long-term Management. London: RCOG Press; 2007.

18. La Scola C, De Mutiis C, Hewitt IK, Puccio G, Toffolo A, Zucchetta $P$, et al. Different guidelines for imaging after first UTI in febrile infants: yield, cost, and radiation. Pediatrics. 2013;131:e665-71.

19. Kimata T, Kitao T, Yamanouchi S, Tsuji S, Kino M, Kaneko K. Voiding cystourethrography is mandatory in infants with febrile urinary tract infection. Tohoku J Exp Med 2013;231:251-5.

20. Massanyi EZ, Preece J, Gupta A, Lin SM, Wang MH. Utility of screening ultrasound after first febrile UTI among patients with clinically significant vesicoureteral reflux. Urology 2013;82:905-9.

21. Nguyen HT, Bauer SB, Peters CA, Connolly LP, Gobet R, Borer $J G$, et al. 99m Technetium dimercapto- succinic acid renal scintigraphyabnormalities in infants with sterile high grade vesicoureteral reflux. J Urol 2000;164:1674-8.

22. Moorthy I, Easty M, McHugh K, Ridout D, Biassoni L, Gordon I. The Presence of Vesicoureteric Reflux Does Not Identify A Population At Risk For Renal Scarring Following A First Urinary Tract Infection. Arch. Dis. Child 2005;90:733-6.

23. Gonzales E, Papazyan JP, Giardin E. Impact of vesicoureteral reflux on the size of renal lesions after an episode of acute pyelonephritis. J Urol 2005;173:571-474.

24. Preda I, Jodal U, Sixt R, Stokland E, Hansson S. Normal dimercaptosuccinic acid scintigraphy makes voiding cystourethrography unnecessary after urinary tract infection. J Pediatr 2007;151:581-4.

25. Fouzas S, Krikelli E, Vassilakos P, Gkentzi D, Papanastasiou DA, Salakos C. DMSA scan for revealing vesicoureteral reflux in young children with urinary tract infection. Pediatrics 2010; 126:513-9.

26. Tekgül S, Riedmiller H, Hoebeke P, Kočvara R, Nijman RJ, Radmayr $\mathrm{C}$, et al. European Association of Urology. EAU guidelines on vesicoureteral reflux in children. Eur Urol 2012;62:534-42.

27. Shaikh N, Spingarn RB, Hum SW. Dimercaptosuccinic acid scan or ultrasound in screening for vesicoureteral reflux among children with urinary tract infections. Cochrane Database Syst Rev 2016;7:CD010657.

28. Pecile P, Miorin E, Romanello C, Vidal E, Contardo M, Valent F, et al. Age-related renal parenchymal lesions in children with first febrile urinary tract infections. Pediatrics 2009;124:23-9. 